\title{
«Smart» Logistics: Problems and Prospects in the Modern World
}

\author{
N. V. Przhedetskaya, K.V. Borzenko, V. V. Sheveleva*, and E.P. Kulkova \\ Rostov state economic university (RINH) 69, B. Sadovaya St., Rostov-on-Don, 344002, Russian \\ Federation
}

\begin{abstract}
The COVID-19 pandemic caused serious damage not only to the economies of a number of countries, but also became a serious test for the entire world economy, causing a crisis that, even according to preliminary estimates, will lead to a deeper and more protracted recession than the global financial and economic crisis of 2008. In the second half of 2020, when COVID-19 vaccines are already in effect, the threat to public health fades into the background, giving way to the economic crisis, and, most importantly, the search for ways out of a difficult socio-economic situation. That is why the study of the impact of the COVID-19 crisis on logistics and the search for crisis management tools in logistics is so relevant. In this article, the authors hypothesize that digitalization as a promising tool for economic crisis management should play an important role in this process. This article identifies the current problems of logistics that arise in the context of the COVID-19 pandemic and the crisis, substantiates the prospects for systematic and highly effective crisis management in logistics based on digitalization, and offers applied recommendations for this.
\end{abstract}

As we mentioned above, the world economies, the economies of countries and regions have undergone significant changes as a result of the COVID-19 pandemic and related problems. The closure of borders, the declaration of an extraordinary regime and the transfer of about $43 \%$ of the economically active population of 78 countries around the world are just some of the consequences that the spread of COVID - 19 has caused. Of course, all this has had a negative and sometimes destructive impact on entire countries and regions, not to mention individual enterprises. Already in March 2020, the damage from the pandemic exceeded $\$ 5$ trillion. According to the WTO forecasts, the decline in world trade turnover this year will exceed 30\%, and world industrial production in 2020 will be the lowest since 1946. [1]

In this regard, research related to the search for ways out of difficult socio-economic circumstances, for which many countries were simply not ready, is of particular relevance. It is also not necessary to postpone the development of strategic initiatives that will allow economies in the future not only to be more flexible and adaptive to adverse conditions, but also give a good impetus to sustainable socio-economic development. It seems to us that it is the digitalization of processes and the introduction of the principles and tools of the

\footnotetext{
* Corresponding author: beloveronika @yandex.ru
} 
digital economy that will be the fundamental direction that can provide answers to many questions and provide solutions to modern problems.

The issue of digitalization of the economy and its prospects is particularly relevant in Russia, and this is also due to the difficult economic situation in which we found ourselves even before the spread of the pandemic and the lack of economic growth for a number of years.

The uneven economic development of the regions, characteristic of the Russian Federation, was reflected in the difference in the position of the territories during the selfisolation regime and in the process of leaving it and returning to the normal functioning of all systems. Unfortunately, the self-isolation regime announced in the country has hurt the pace of business development. For example as a result of restrictions, the closure of borders between countries and regions, the number of economic entities in the Rostov region decreased by $4 \%$, and the main blow fell on wholesale and retail trade enterprises (the drop was $8 \%$ and $2.7 \%$, respectively). [2]

The peculiarity of the functioning of logistics systems in the conditions of existing restrictions is that on the one hand, these restrictions in the activities of the transport and logistics complex were supposed to stop the spread of the epidemic, but, on the other hand, the paralysis of this area leads to the risk of shortages.

The issues of logistics development are widely covered in the literature and are actively discussed in numerous published works of Russian and foreign authors, including S. B. Moreyskaya, N. A. Osintsev, A. N. Rakhmangulov, A.V. Sladkovsky, V. V. Baginova, V. I. Sergeev, P. V. Solodukha, P. A. Chernovalov, I. Tszyu, Yu. A.Shcherbanin, Xiu Bagh, S. Gupta, G. Chen, Yu. Lin, M. N. Foster. However, the specifics of the functioning of logistics systems in the context of the global COVID-19 pandemic are not disclosed in these publications and therefore need additional research.

The issue of adaptation to the new factors caused by the transition to the digital economy has been repeatedly raised in scientific works, since modern economists associate economic growth with the development of innovative digital platforms. According to the McKinsey Global Institute, by 2025, GDP growth due to digitalization in a number of the world's leading economies will increase dramatically. So, in China, such an increase can be up to $22 \%$, in the United States - about 1.6 - 2.2 trillion dollars, in Russia - from 19 to $34 \%$ of the total expected GDP growth. [3]

The process of digitalization changes the established order and nature of relations between market participants. In addition, current trends have an impact on the development and implementation of new mechanisms for managing logistics processes both at the level of the national economy and at the level of a particular region.

The modern Russian region is forced to solve not only immediate problems, but also to take care of the long-term development of all regional socio-economic systems. That is why the Strategy of socio-economic Development of the Rostov Region - 2030 was formulated in the Rostov region. The main task of this strategy is to achieve a leading position in the digitalization of the economy and provide high-quality education in the field of information technology.

The authorities of the region pay a special role to the implementation of innovative projects in the field of telemedicine, the creation and development of specialized IT clusters, platforms for training soft skills, etc. Of course, logistics systems and their longterm development occupy a special niche in the structure of both the national and regional economy, since this determines the degree of competitiveness of the region and its position in the digital environment of the country. [4]

The modern world, with its translation of business and personal relationships from real to virtual-real format, leads to the need to analyze the place of logistics in the economic system. Accordingly, the region should ensure the development and development of 
markets for digital goods, services and products, and promote the active use of digital technologies and innovative business models. [5]

However, the crisis caused by the spread of COVID-19 has led to the need to accelerate the process of restructuring and modifying logistics systems, adapting them to new global and regional conditions.

The transition to «smart» logistics can become just such a universal tool that allows you to adapt to a changed world with minimal costs. However, here we face very significant problems that can be solved by using the tools of the digital economy.

The first problem is related to the disruption of value chains and the unpredictability of restrictions imposed on the movement of logistics flows due to changes in the epidemiological situation in different territories (regions of Russia and countries of the world). Bans on logistics links with certain territories cause increased logistics complexity in the context of the COVID-19 crisis.

«Smart» logistics with the use of artificial intelligence allows you to solve this problem with the help of intelligent optimization of value chains and flexible routing. Thanks to «smart» logistics, Russian enterprises can successfully adapt to the conditions of high uncertainty and risk and make timely rational decisions about the restructuring of logistics flows.

The second problem is the increased requirements for logistics security. In addition to the standard requirements for the safety of goods, their delivery on time, etc., in the context of a pandemic, there are increased requirements for the safety of goods for human life and health, since it is impossible to prevent the transmission of infection through manufactured, sold and consumed goods and services. Accordingly, the tightening of sanitary standards during the epidemic increases the cost of logistics and reduces its efficiency.

To solve this problem, we can offer to automate logistics processes. Reducing human contact reduces the risk of infection, and automated logistics operations based on robots and manipulators are characterized by the highest level of safety in terms of sanitation. Automatic loading and unloading of goods can be supplemented by digital geolocation and ubiquitous computing, which will provide information support for the logistics of each product with an expanded description of compliance with sanitary standards.

The robotization of logistics processes will lead to a reduction in personnel costs, the introduction of electronic document management will allow not only to quickly find the necessary documents, but also to store a large array of information at no special cost.

The process of automating work processes is one of the most striking manifestations of the digital economy and the changes taking place in this regard in the world. By 2036, it is expected that $50 \%$ of all global workflows will be automated. [3]

And, accordingly, the sooner the regional authorities and enterprises are ready for these changes, the higher the level of competitiveness of the region will be.

The third problem is the management of personnel in the conditions of instability of the enterprise's need for them. Forced downtime due to restrictions imposed in the context of the COVID-19 pandemic leads to a decrease in the interest of enterprises in employees and causes losses, the main part of which is associated with the need to fulfill social guarantees of business. As a recommendation to solve this problem, it is proposed to transfer some of the employees to remote work. In logistics automation, remote work involves remote control of manipulators, setting up artificial intelligence, and tracking digital data about logistics flows.

It should be noted here that no digitalization is possible without the motivation of personnel and without the systematic development of their professional skills, training in flexible skills. Of particular importance in the changing world is the development of such qualities as creativity, the ability to cooperate, sociability, systematic thinking, as well as emotional intelligence, i.e. the ability to effectively manage emotions. All these skills are 
required not only for a more painless adjustment to remote work formats, but will also be very much in demand in an already changed world.

The fourth problem faced by all countries that survived the COVID-19 epidemic is the decline in living standards in the crisis and the decline in logistics efficiency. The market capacity remains the same, that is, there is a high demand for goods and services in the economy, but effective demand is decreasing. As a result, entrepreneurs have to reduce the cost of production to reduce the cost of logistics services. The most promising solution to this problem is the transition from «just-in-case» logistics (inventory warehousing) to «justin-time» logistics.

With the help of modern cloud technologies and the development of online commerce, it is advisable to receive pre-orders, aggregate them and produce products in large batches to extract «economies of scale». This will reduce costs and reduce the cost of logistics services while maintaining their high quality.

In addition to the listed and analyzed problems faced by logistics companies during the COVID-19 pandemic, we can also add such problems as: restrictions and delays in the delivery of goods between countries; financial difficulties for industry operators; supply shortages.

The development of digital technologies and digitalization of processes will solve many problems in logistics during the COVID-19 pandemic, as well as adapt to the changed world after the epidemic. It is the digital economy, changing the existing economic structure, that helps to form economic relations between market participants at a new level. In the digital economy, logistics can be thought of as an element of the institutional infrastructure of a country or region. In a modern world built on active innovation, logistics will also allow enterprises to optimize costs, ensuring efficient flow of flow processes and speeding up interactions with partners and consumers. [4-6]

There are a number of effective digital tools that logistics can use in modern conditions to overcome problems, implement strategic goals and objectives. The main of these tools are presented in table 1.

Table 1. Characteristic features of digital technologies used in the modern economy and logistics [7]

\begin{tabular}{|l|l|}
\hline \multicolumn{1}{|c|}{ Innovative technology } & \multicolumn{1}{c|}{ Typical features } \\
\hline Cognitive technologies & $\begin{array}{l}\text { big data processing technologies for unstructured (often } \\
\text { textual) information }\end{array}$ \\
\hline Cloud technologies & $\begin{array}{l}\text { technologies that provide fast, easy network access to a } \\
\text { large array of resources generated at the user's request }\end{array}$ \\
\hline Internet of Things (IoT) & $\begin{array}{l}\text { a technology that allows you to collect a variety of data via } \\
\text { remote access and manage them in real time }\end{array}$ \\
\hline Machine Learning & $\begin{array}{l}\text { a set of mathematical methods of analysis and statistical } \\
\text { processing of information, optimization and programming } \\
\text { methods that allow you to identify hidden patterns and take } \\
\text { them into account when developing a management decision }\end{array}$ \\
\hline Blockchain & $\begin{array}{l}\text { a set of encryption algorithms that allow you to protect } \\
\text { databases that can store all information about all } \\
\text { transactions between the subjects of commodity distribution } \\
\text { systems that have a timestamp and a link to the previous } \\
\text { information blocks, which eliminates the falsification of the } \\
\text { accumulated data array }\end{array}$ \\
\hline
\end{tabular}

The table shows only some of the technologies that can be implemented in the enterprise already in the present time. We can add to the list such breakthrough technologies as cargo delivery by drones or the introduction of self-driving cars, 3-D 
printing or the use of Augmented Reality. Already from this, we can draw a conclusion about the prospects for the development of logistics in the digital world and its opportunities to achieve strategic goals. Unfortunately, not all of these tools are yet available to representatives of small and medium businesses in Russia, especially given the fact that it is the small and medium business sectors that have been most severely affected by the crisis caused by the COVID-19 pandemic.

In order for enterprises to master and implement innovative digital technologies, it is necessary to support federal and regional authorities and their joint activities to create a favorable infrastructure. Entrepreneurs should be aware that the digital development model will allow them to implement common standards for the implementation of logistics operations, to form a coordinate system for evaluating the results of activities, staff motivation, etc. [6]

Currently, it is possible to observe and analyze the process of transformation of logistics flows on a global scale. The main trend, as it seems to us, is the restructuring of the existing models of production and sales, the movement of goods, services, capital and labor in accordance with the new conditions of the digital development model. And, most likely, the COVID-19 pandemic and the subsequent crisis phenomena will give an impetus to accelerate the transformation processes and enter a new round of socio-economic development.

So, it was proved that logistics in the conditions of COVID-19 faces numerous problems, but all of them can be systematically solved on the basis of digitalization. At the same time, it is necessary to recognize that the introduction of digital technologies in logistics requires large-scale investments in digital innovations, which are difficult to attract in a crisis. It is also necessary to improve the skills of employees to master their digital competencies. This creates financial and educational barriers to the practical implementation of the proposed author's recommendations.

For example, the Strategy of socio-economic Development of the Rostov Region-2030 sets a very ambitious goal for the regional authorities and the business community to achieve a leading position in the digitalization of the economy by providing high-quality education in the field of information technology. However, according to the rating of the quality of school education, the Rostov region was on the 57th place and received 43.6 points out of 100. The weaknesses identified by the analysts are the relatively low availability of computers and laboratory equipment and the weak practical skills of graduates. [8]

Therefore, as we can see, the declarations on the transition to the digital model of the economy still face very significant difficulties that need to be solved, starting from the basics.

Therefore, expanded state support for logistics enterprises in the context of the COVID19 crisis is needed. This support should include not only funding for digitalization, but also educational support for the training of digital personnel. In this case, integration mechanisms for the development of entrepreneurship are particularly useful and should be used, the key of which should be clusterization, public-private partnership and innovation networks.

As a result, we can conclude that the new challenges of the time in the form of digitalization of logistics infrastructure lead to the need to introduce modern tools that can ensure the interaction of innovation and production, creating a single ecosystem. However, for an effective transition to a digital format of functioning, joint efforts of the federal and regional authorities, as well as the business community, are necessary. Only purposeful activities aimed at creating optimal conditions for entrepreneurs to realize the potential of «smart» logistics will give the necessary impetus to solve strategic tasks for a confident transition of the region to a stable functioning digital economy. 


\section{References}

1. Losevskaya,S. A., Linetskaya,T. N. Influence of coronavirus infection on pub-lic catering enterprises, Expert of 2020:Collection of articles of International re-search conf. - Petrozavodsk, P.115-119 (2020)

2. Coronavirus Pandemic on Don was not experienced by $4 \%$ of subjects of trade and public catering [Electronic resource]. - Mode of access: https://rostov.aif.ru.

3. Aptekman, A., Kalabin, B., Klintsov, V. Digital Russia: new reality [Electronic resource]. - Mode of access: https://www.mckinsey.com.

4. Rostov region: business support measures to overcome the consequences of a new coronavirus infection. https://minsvyaz.donland.ru/documents/active/58923/ https://minsvyaz.donland.ru/upload/uf/e4b/2823172_531053326_531053546.pdf

5. Borisova V.V. Digital institutional transformation of region's logistics infrastructure, Vestnik of Rostov State University of Economics (RINH), № 2(70), P. 45 - 53 (2020)

6. Evtodieva T. E., Polubotko A. A. Logistics in digital economy, Vestnik of Rostov State University of Economics (RINH), № 1(69), P. 35 - 43 (2020)

7. Legislative experiment with introduction of digital innovations, Corporate cloud provider [Electronic resource]. - Mode of access: https://habr.com.

8. The Rostov region was in the basement of the rating of the quality of education. The level of education on the Don was twice as bad as in Moscow // https://161.ru/text/education/2021/03/16/69814760/ 